\title{
Prevalence and correlates of psychological distress symptoms among patients with substance use disorders in drug rehabilitation centers in urban Nepal: a cross-sectional study
}

Bishal Gyawali ${ }^{1,2^{*}}$, Bishnu P. Choulagai ${ }^{3}$, Damaru Prasad Paneru ${ }^{4}$, Meraj Ahmad ${ }^{5}$, Anja Leppin ${ }^{6}$ and Per Kallestrup ${ }^{1}$

\begin{abstract}
Background: The burden of substance misuse in developing countries is large and increasing, with negative consequences for physical and psychological health. Substance use disorders and psychological distress commonly co-exist, however few studies have examined this relationship in developing countries, including Nepal. Our aim was to investigate the prevalence of psychological distress symptoms and associated factors among patients with substance use disorders attending drug rehabilitation centers in Nepal.

Methods: We conducted a cross-sectional study including 180 patients attending drug rehabilitation centers in the Kathmandu Valley region of Nepal. We used the 6-item Kessler scale (K6) to measure symptoms of psychological distress, and data on socio-demographics, behavioral and psychosocial factors. Multivariable analyses were used to identify factors associated with distress.

Results: The prevalence of high psychological distress symptoms among patients with substance use disorder was $51.1 \%$. The mean score found on the K6 was $12.22(S D=5.87)$. Outcomes of multivariable analyses demonstrated various factors associated with symptoms of psychological distress, including age ( $\beta=-0.122,95 \% \mathrm{Cl}=-0.218$; -0.026 ), education ( $\beta=2.694,95 \% \mathrm{Cl}=0.274 ; 5.115)$, severity of drug abuse (Drug Abuse Screening Test-10-DAST10) $(\beta=0.262$, $95 \% \mathrm{Cl}=0.022 ; 0.502$ ), and family functioning (Adaptability, Partnership, Growth, Affection and Resolve-APGAR) ( $\beta=-0.525,95 \% \mathrm{Cl}=-0.787 ;-0.264)$.

Conclusions: High psychological distress symptoms are common in patients with substance use disorder in Nepal. Demographics (age, education), behavioral (drug abuse severity), and psychosocial factors (family functionality) were associated with psychological distress symptoms. If confirmed by future longitudinal studies such characteristics may assist in identifying groups at risk for co-morbid psychological distress symptoms among patients with substance use disorders. Future treatment approaches for substance use disorders should address co-existing mental illness in Nepal.
\end{abstract}

Keywords: Substance use disorders, Distress, Kessler-6-item scale, Rehabilitation, Nepal

\footnotetext{
* Correspondence: bishalforu@hotmail.com

${ }^{1}$ Center for Global Health, Department of Public Health, Aarhus University,

Bartholins Allé 2, Building 1261, 2:15, DK-8000 Aarhus C, Denmark

${ }^{2}$ Nepal Development Society (NEDS), Bharatpur, Nepal

Full list of author information is available at the end of the article
} 


\section{Background}

Substance use disorders (SUDs), according to DSM-5, refer to a problematic pattern of use of alcohol or another substance causing clinically significant impairment in daily life or noticeable distress. These disorders are prevalent worldwide and may lead to a wide range of physical, psychological and emotional health problems. SUDs are often associated with considerable psychiatric disorders, including depression and anxiety [1]. Various epidemiological $[2,3]$ as well as clinic based $[4,5]$ studies from Western countries have reported a high prevalence of comorbidity of SUDs and psychiatric disorders. Mental disorders and SUDs were one of the leading causes of disease burden in 2010 accounting for $7.4 \%$ of global Disability-Adjusted Life Years (DALYs) and $22.9 \%$ of global Years Lived with Disability (YLDs) [6]. This is a particular challenge for developing countries where the burden of mental health and SUDs is predicted to increase [6] but which-due to resource restrictions and limited prioritization in health care planning and workforce development-often face problems in fully addressing these problems. This is also the case for Nepal. Data about prevalence of mental health problems in population groups with SUDs are limited. However, a recent study of 188 consecutively admitted alcohol use disorder (AUD) patients in treatment facilities in Kathmandu found the lifetime and 12-month prevalence rates of major depression to be 45 and $36 \%$ respectively [7]. In another smaller-scale cross-sectional study of alcohol-dependent patients in Eastern Nepal, 38 out of 60 patients (63.3\%) had one or more psychiatric disorders [8].

This substantial level of psychiatric comorbidity raises concern since depression and anxiety may not only influence help-seeking behavior, such as obtaining diagnosis and treatment for SUDs [9] as well as adherence to treatment [10]; they may decrease quality of life [11], increase risk of relapse [12], of social isolation [13] and risk of early mortality [14]. Risk factors for depression and anxiety among SUD patients in Western countries have been reported to be female gender [15], younger age, low family income and being single [16].

In Nepal, mental health risk factors in groups with SUDs have so far rarely been investigated. However, Neupane et al. in a study of 188 Nepalese patients being treated for AUDs reported that a main factor to be associated with major depression was not being married [7]. A similar finding was also reported by an earlier smallscale study by Pradhan et al. [17]. Further, coming from an urban as compared to a rural area and living in a nuclear family compared to a joint or extended family were positively associated with risk of depression while age, gender, education and income were unrelated [7]. However, there is a general paucity of information regarding potential behavioral and psychosocial correlates of psychological distress, and particularly regarding the factors, which potentially mediate associations between socio-demographic characteristics and mental health for instance, stress experience, or familial functionality. Thus, while family type and marital status have been reported to be relevant [7, 17], quality of family relationships might be just as or even more important. A study conducted in India, for instance, reported associations between poor relationships with family, poor physical health, experiences of violence and sexual abuse with depression and anxiety [18]. Another factor, which might be relevant in the socio-cultural context of Nepal, is the stigma involved in substance use/abuse. Neupane et al. in a study on treatment seeking for alcohol problems in Nepal found considerable differences in searching for treatment depending on whether alcohol consumption was considered a social taboo or not [19]. Similarly, it might be expected that patients who see themselves as socially stigmatized by being treated for substance abuse in a clinic might be more likely to experience psychological distress.

Despite the publication of some studies highlighting the high levels of psychiatric disorders in patients with SUDs, there continues to be a dearth of evidence examining the associated factors of psychological distress in SUDs, especially in the Nepalese socio-cultural context. A greater understanding of the specific factors associated with psychological distress among patients with SUDs is however necessary to develop appropriate and effective interventions. The aim of this study is to investigate the prevalence of psychological distress symptoms and associated factors among patients with substance use disorders attending drug rehabilitation centers in Nepal.

\section{Methods}

\section{Study design, population and setting}

This was a cross sectional study using convenience sampling technique. Data were collected between March and July 2014 in seven drug and alcohol rehabilitation centers in Kathmandu Valley of Nepal. These centers provided a therapeutic environment for detoxification of patients with SUDs. The Kathmandu Valley has a population of approximately 2.5 million, the majority of who are Hindus and Buddhists, while Muslims and Christians are religious minorities [20] Ethnic and caste groups comprise Dalits, disadvantaged and relatively advantaged Janajatis, disadvantaged non-Dalits, religious minorities, and upper caste groups [21]. The literacy rate in Kathmandu is $86.3 \%$, and Nepali is the most widely spoken language [20]. Mental health care is provided to some extent at the outpatient mental health facilities, although private clinics and clinics funded by NonGovernment Organizations (NGOs) also exist [22]. Only few NGOs/private organizations in urban areas run 
rehabilitation services that include therapeutic detoxification and 12-step programs. At the time of the study, each rehabilitation center was providing care for between 30 and 90 patients.

\section{Data collection tools}

Data on demographics, socio-economic conditions, behavioral (alcohol abuse severity and drug abuse severity), psychosocial factors (stressful life events, perceived stigma, and family functionality) and psychological distress symptoms were collected using a self-administered questionnaire. Prior to questionnaire development, an extensive literature review was conducted to identify associated factors for psychological distress.

We used a standardized questionnaire to collect sociodemographic information, including age, gender, ethnicity, marital status, education, occupation, monthly income and living situation. Age and monthly income were assessed as continuous variables. Ethnicity was grouped into three categories (Upper caste, Janajati and Others). Marital status was dichotomized into married and unmarried. Education was grouped into three categories (primary, secondary and university). Occupation was dichotomized into employed and unemployed. Living situation was dichotomized into living alone and with family. Stressful life events were defined as whether or not any serious personal or emotional problem had occurred during the past 12 months (no/yes).

We used the Kessler-6 (K6) Psychological Distress Scale to measure distress symptoms, a standardized and validated screening tool for non-specific psychological distress, including depression and anxiety [23]. The K6 offers the advantage of being a broader screening tool compared to some of the other locally validated mental health screens such as the General Health Questionnaire12 (GHQ-12), and Patients Health Questionnaire-9 (PHQ-9), because it is not specific to a single disorder and has been validated to screen for common disorders in developing country settings [24]. The scale is available in a Nepali version [25] and has been used previously in Nepal [26], as well as in a variety of cultural settings in different parts of the world [27, 28]. The K6 uses a Likert scale to establish how often an individual has experienced psychological distress over the preceding 30 days. Scores range from 0 to 24 with higher score indicating better outcomes. A $\mathrm{K} 6$ score of greater than 12 has been defined as indicating high psychological distress [29]. Psychological distress assessment was performed on the seventh day after patients' admission to the rehabilitation center.

We assessed participants' risk of alcohol abuse using the Alcohol Use Disorder Identification Test (AUDIT), a 10-item screening measure designed to identify drinkers at risk for alcohol abuse or dependence [30]. Scores ranged from 0 to 40 : $0-7$ indicates low risk; $8-15$ indicates moderate risk or hazardous drinking; 16-19 indicates high-risk or harmful drinking; and a score of 20 or above indicates possible dependence [30].

Drug use was measured using the Drug Abuse Screening Test-10 (DAST-10), which quantitatively assesses the severity of drug-related problems. A single summary score reflects the number of drug abuse items endorsed. A score ranging from 1 to 2 indicates low risk, 3-5 indicates moderate severity level, 6-8 indicates a substantial level and a score ranging from 9 to 10 indicates a severe level of problems [31].

We used the Perceived Stigma of Substance Abuse Scale (PSAS) which is an eight item self rated scale to look at stigma experienced by the substance users due to their substance use [32]. All items are marked on a Likert-type scale with four options ('totally disagree' to 'totally agree'). Six of the eight items are reverse scored. The scale ranges from 8 to 12, higher scores indicating presence of perceived stigma. Luoma et al. developed and validated the scale which is easy to administer and has shown a good face and construct validity and an acceptable internal consistency [32].

Perceived family functionality was measured by the Adaptability, Partnership, Growth, Affection and Resolve (APGAR) Scale, which comprises questions about key components of family function [33]. A score of 7 to 10 suggests a highly functional family, a score of 4 to 6 suggest a moderately dysfunctional family and a score of 0 to 3 suggests a severely dysfunctional family.

\section{Procedure}

Three specially trained research assistants with a health professional background carried out the administration of the questionnaires in training rooms available in each center. The research assistants introduced themselves at first and then briefly explained the purpose of the study. Subsequently, an informed consent form was distributed to all eligible participants and later collected. Eligible participants were patients undergoing residential treatment for SUDs, including alcohol abuse and drug abuse who were 16 years or above, and able to read and write in Nepali. Those who were reluctant to participate in the study and who had cognitive impairments were excluded from the study. Presence of cognitive impairment was assessed by asking patients whether they had ever been diagnosed by a physician as having memory problems. In case of any literacy difficulty, the consent form was read aloud. The consent form informed participants about the purpose of the study and advised that participation was voluntary. Participants were assured verbally and on paper that all information provided would be kept strictly confidential and not used except for the study purpose. All participants who agreed to participate were provided an informed consent form to sign. After 
obtaining a written informed consent, the research assistants distributed the self-administered questionnaires and offered necessary instructions for the participants to fill it out anonymously. The study protocol received ethical approval from the Manipal College of Medical Sciences, Pokhara, Nepal.

\section{Statistical analysis}

We conducted descriptive analyses to identify characteristics of the study sample. We analyzed the K6 data as a continuous outcome. Analyses of associated factors were conducted in two stages: i) the association of each variable with distress was assessed through univariate linear regression models; ii) multivariate analyses were carried out in the second stage among variables that showed an association at $p<0.05$ in the first stage. To guide these multivariable analyses, we used an analytical framework based on hierarchical relationships of factors associated with Psychological Distress Symptoms Fig. 1.

This approach enabled us to take account of hierarchical relationships between predictors, and balance reliance on statistically significant associations [34]. Furthermore, we arranged associated factors into three levels: the top level consisted of socio-demographic factors, which we considered to act directly, or indirectly through intermediate factors to cause distress; the next level included

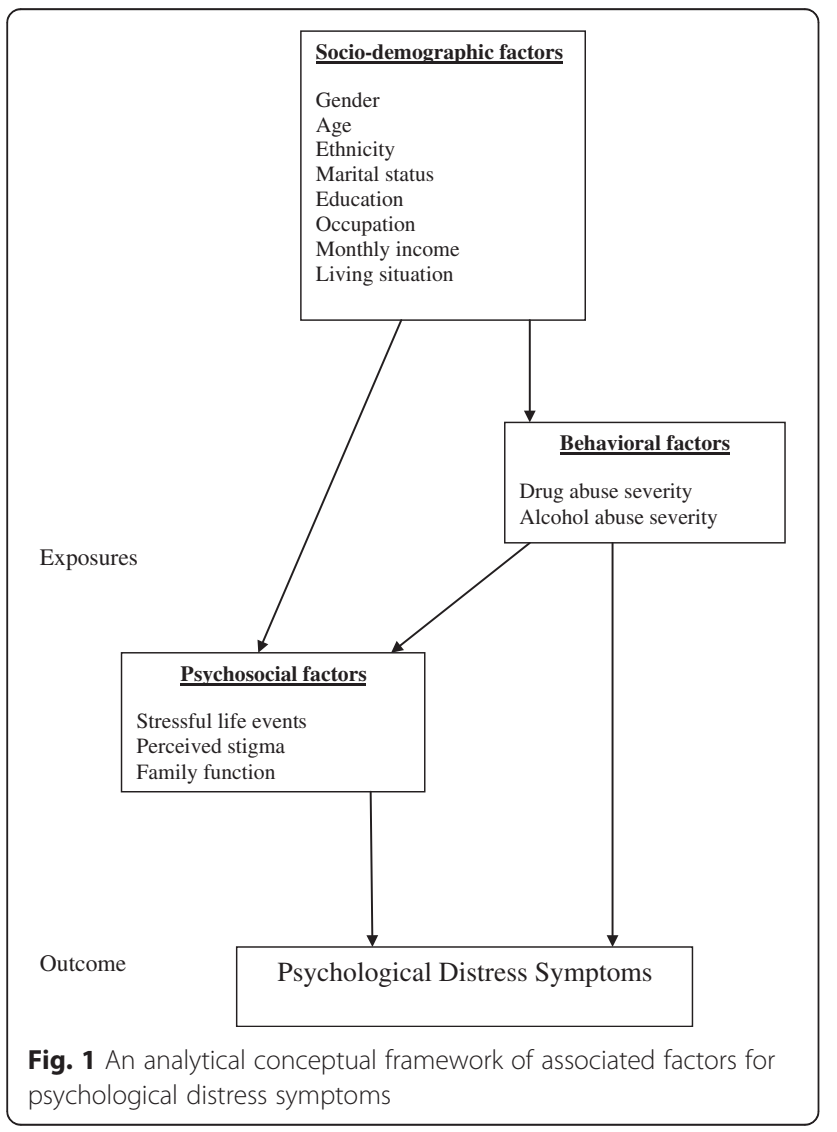

behavioral factors; the lowest level included psycho-social factors as the most proximal predictors. Correlation analyses and $t$-tests were used to identify significant factors associated with psychological distress. Reliability was assessed with Cronbach's alpha [35]. All statistical analyses were conducted using Statistical Package for Social Science 22.0 (SPSS 22.0) software [36].

According to the framework, groups of variables were entered in hierarchical order into a multivariable modeling procedure. A similar approach has been used previously to assess predictors of common mental disorders [37, 38]. The assumptions of linear regression (outliers, normality of distribution and linearity) were checked (using box plot, histogram, q-q plot and scatter plot). Tolerances for the parameter estimates were examined to assure that multicollinearity was not a problem.

\section{Results}

All of the 180 participants completed and returned the questionnaire. Socio-demographic characteristics of participants are summarized in Table 1 . The study population was mostly males $(85.6 \%)$ and the mean age of the participants was 29.08 years $(\mathrm{SD} \pm 9.98)$. More than half of participants (51.7 \%) belonged to Upper Caste Groups and $54 \%$ were unmarried. More than $52 \%$ of the participants were unemployed. Nearly $88 \%$ were living with family. The average monthly income of participant's household was Rupees 23,030.60 (SD \pm 8628.54 ) or 230.31 US Dollars (1 Nepali Rupees $=0.01$ US Dollar, July 2014). The mean DAST score was 5.42 points $(\mathrm{SD}=3.918)$. The internal consistency of the DAST scale was found to be $\alpha=0.86$. The mean AUDIT score was 17.03 points $(\mathrm{SD}=12.078)$ and Cronbach's alpha for the scale was 0.85 . The mean on the perceived stigma scale was 24.32 points $(S D=5.095)$. Internal consistency of the stigma scale was $\alpha=0.72$. The mean APGAR score was 5.69 points $(\mathrm{SD}=2.907)$. The internal consistency of the APGAR scale was $\alpha=0.84$. The K6 score distribution was approximating a normal distribution with a mean score of 12.22 and standard deviation (SD) of 5.87. The mean $\mathrm{K} 6$ score for male and female participants were $11.84 \pm 5.91$ and $14.42 \pm 5.18$ respectively. The internal consistency of the K6 was Cronbach's alpha $=0.89$. The overall prevalence of high psychological distress symptoms among participants was $51.1 \%(n=92)$.

Univariate correlational analyses and t-tests were performed initially between individual K-6 scale scores and three types of variables: socio-demographic variables (age, gender, ethnicity, marital status, education, occupation, living situation, and monthly income), behavioral variables (severity of substance abuse: scores on DAST and AUDIT) and psychosocial variables (stressful life events, perceived stigma, and scores on APGAR) (Table 2). We found 
Table 1 Sample characteristics

\begin{tabular}{|c|c|c|}
\hline Characteristics & M or $n$ & $\%$ or SD \\
\hline Age & 29.08 & 9.981 \\
\hline \multicolumn{3}{|l|}{ Gender } \\
\hline Male & 154 & 85.6 \\
\hline Female & 26 & 14.4 \\
\hline \multicolumn{3}{|l|}{ Ethnicity } \\
\hline Upper caste & 93 & 51.7 \\
\hline Janajati & 82 & 45.6 \\
\hline Others & 5 & 2.8 \\
\hline \multicolumn{3}{|l|}{ Marital status } \\
\hline Married & 83 & 46.1 \\
\hline Unmarried & 97 & 53.9 \\
\hline \multicolumn{3}{|l|}{ Education } \\
\hline Primary & 20 & 11.1 \\
\hline Secondary & 114 & 63.3 \\
\hline University & 46 & 25.6 \\
\hline \multicolumn{3}{|l|}{ Occupation } \\
\hline Employed & 85 & 47.2 \\
\hline Unemployed & 95 & 52.8 \\
\hline \multicolumn{3}{|l|}{ Living situation } \\
\hline Alone & 22 & 12.2 \\
\hline With family & 158 & 87.8 \\
\hline \multicolumn{3}{|l|}{ Stressful life events } \\
\hline Yes & 116 & 64.4 \\
\hline No & 64 & 35.6 \\
\hline Monthly income (Rupees) & $23,030.60$ & 8628.54 \\
\hline Drug abuse severity (DAST-10) & 5.42 & 3.918 \\
\hline Alcohol abuse severity (AUDIT) & 17.03 & 12.078 \\
\hline Perceived stigma & 24.32 & 5.095 \\
\hline Family functioning (APGAR) & 5.69 & 2.907 \\
\hline
\end{tabular}

Note: $M$ mean, $n$ group size, $S D$ standard deviation, DAST-10 drug abuse screening test-10, AUDIT alcohol use disorder identification test; APGAR adaptability, partnership, growth, affection and resolve

significant correlations and t-test differences between the K6 scores and age, gender, marital status, education, score on DAST, perceived stigma, and APGAR.

We, then, performed hierarchical multiple regression analyses with those socio-demographic variables, behavioral variables, and psychosocial variables that had been significant in the univariate analyses as predictors and the K-6 score as the dependent variable (Table 3). The socio-demographic variables age, gender, marital status, and education were entered into the first block and accounted for $13.4 \%$ of the variance in $\mathrm{K} 6$ scores [F $(4,175)=6.788]$. The second block included the DAST score and explained an additional $4.1 \%$ of the variance $[\mathrm{F}(5,174)=7.383]$. Block three added perceived stigma
Table 2 Univariate analysis of K6 scores in relation to socio-demographic characteristics, behavioral characteristics, and psychosocial characteristics

\begin{tabular}{|c|c|c|c|c|c|}
\hline$N=180$ & M or $n$ & $\%$ or SD & $\mathrm{t}$ & r & $P$-value \\
\hline \multicolumn{6}{|c|}{ Socio-demographic characteristics } \\
\hline Age (years) & 29.08 & 9.981 & & -0.3 & $p<0.001$ \\
\hline Female & 26 & $(14.4 \%)$ & 1.99 & & 0.048 \\
\hline Upper Caste & 93 & (51.7 \%) & 1.127 & & 0.256 \\
\hline Unmarried & 97 & (53.9 \%) & 2.031 & & 0.044 \\
\hline Primary education & 20 & (11.1\%) & 2.226 & & 0.027 \\
\hline Unemployed & 95 & $(52.8 \%)$ & 1.776 & & 0.078 \\
\hline Monthly income & $23,030.60$ & 8628.54 & & -0.39 & 0.700 \\
\hline Living alone & 22 & $(12.2 \%)$ & 1.247 & & 0.313 \\
\hline \multicolumn{6}{|l|}{ Behavioral characteristics } \\
\hline Alcohol abuse severity & 17.03 & 12.078 & & 0.127 & 0.136 \\
\hline Drug abuse severity & 5.42 & 3.918 & & 0.391 & $p<0.001$ \\
\hline \multicolumn{6}{|l|}{ Psychosocial characteristics } \\
\hline Stressful life events & 116 & (64.4 \%) & 0.703 & & 0.483 \\
\hline Perceived stigma & 24.32 & 5.095 & & 0.339 & $p<0.001$ \\
\hline Family functionality & 5.69 & 2.907 & & 0.315 & $p<0.001$ \\
\hline
\end{tabular}

and the APGAR score and explained an additional $8.7 \%$ of the variance $[F(7,172)=8.728]$.

Summary statistics for the complete model are presented in Table 4. The final regression model accounted for a significant $26.2 \%$ of the explained variance in K6 score $[\mathrm{F}(7,172)=10.14]$.

Age $(\beta=-0.12 ; 95 \% \mathrm{CI}-0.218,-0.026 ; p=0.013)$ and education $(\beta=2.694 ; 95 \% \mathrm{CI}=0.274,5.115, p=0.029)$ were the only socio-demographic variables that were significant predictors in this model. In addition, scores on the DAST $(\beta=0.262 ; 95 \% \mathrm{CI}=0.022,0.502 ; p=0.032)$ and the APGAR $(\beta=-0.525 ; 95 \% \mathrm{CI}=-0.787,-0.264$; $p<0.001)$ were significantly related to the K6 score in the complete model.

\section{Discussion}

The present results show that $51.1 \%$ of patients being treated for SUDs in Kathmandu Valley treatment centers experienced high psychological distress symptoms. As expected this rate is considerably above those found in community settings for the general population of Nepal, where studies have reported psychological distress rates from $9.8 \%$ [39] to $33.7 \%$ [40]. Two other studies have specifically reported distress data for patients treated for SUDs in Nepal, one reporting lower, the other considerably higher distress prevalence. In the study by Neupane et al. only 51 (30.2\%) out of 169 patients with AUD had recently experienced depressive symptoms as measured by the Hopkins Symptoms Check List-25 [37] and $36 \%$ had 
Table 3 A hierarchical multiple regression analysis of determinants of K6-scores: contributions of each variable block to changes in $\mathrm{R}^{2}$

\begin{tabular}{llllllll}
\hline Determinants & & $\mathrm{R}^{2}$ & $\Delta \mathrm{R}^{2}$ & $\mathrm{~F}$ & $\mathrm{df}$ & $\Delta \mathrm{F}$ & $\mathrm{Sig} \Delta \mathrm{F}$ \\
\hline Block 1 & Socio-demographics & 0.134 & 0.134 & 6.788 & 4,175 & 6.788 & $p<0.001$ \\
Block 2 & Behavioral & 0.175 & 0.041 & 8.587 & 5,174 & 7.383 & 0.004 \\
Block 3 & Psychosocial & 0.262 & 0.087 & 10.148 & 7,172 & 8.728 & $p<0.001$ \\
\hline
\end{tabular}

Note: $R^{2}, F$ and df describe the overall regression equation after each block has been entered into the model. $\Delta R^{2}, \Delta F$, and significance $\Delta F$ describe the contributions of each individual block

experienced at least one major depressive episode assessed by the WHO's Composite International Diagnostic Interview in the preceding 12 months [7]. A main factor explaining the discrepancy between prevalence rates in the two studies may lie in the different time window for distress prevalence estimation. While the present study assessed distress at the end of the first week of treatment asking for experience in the preceding four weeks, the study by Neupane et al. assessed symptoms during the preceding two weeks excluding the week post-admission, since the later is specifically stressful, difficult and often painful period. Including distress ratings from this period may, due to their transitory nature, lead to overestimation of longer-term distress experience. Further, the present study included slightly higher proportions of younger respondents who are known to report higher distress rates [37, 41]. Another study from Nepal by Pradhan et al., including 53 patients treated from AUD, found as many as $94.3 \%$ of patients suffering from depressive symptoms as measured by the Hamilton Depression Rating Scale [17]. This extremely high rate is explained by the fact that the study included only patients who had been admitted to the psychiatric ward of the hospital with the diagnosis of mental or behavioral disorder due to alcohol use.

Comparisons with prevalence data from other countries also show a wide range of distress rates. Comparable findings to those of the present study where reported by a Jamaican study of 56 patients treated for SUDs [42], where $42.8 \%$ reported severe or very severe depression symptoms on the Kessler-10- scale and a study from Hunan Province, China, where $43 \%$ of heroindependent patients in a treatment center showed depressive symptoms and $53 \%$ anxiety symptoms as assessed by

Table 4 Multivariate analysis of K6 scores

\begin{tabular}{llll}
\hline Determinants & $\beta(95 \% \mathrm{Cl})$ & $\mathrm{SE}$ & $P$-value \\
\hline Age & $-0.122(-0.218 ;-0.026)$ & 0.049 & 0.013 \\
Female & $1.206(-0.983 ; 3.394)$ & 1.109 & 0.278 \\
Unmarried & $-0.610(-2.421 ; 1.202)$ & 0.918 & 0.507 \\
Primary education & $2.694(0.274 ; 5.115)$ & 1.226 & 0.029 \\
Drug abuse severity & $0.262(0.022 ; 0.502)$ & 0.122 & 0.032 \\
Family functionality & $-0.525(-0.787 ;-0.264)$ & 0.132 & $p<0.001$ \\
\hline
\end{tabular}

Note: $\beta$ regression coefficient, $C l$ confidence interval, $S E$ standard error the Zung's Self-Rating Depression (SDS)/Self-Rating Anxiety Scales (SAS) [43].

In contrast, much higher prevalence rates were reported by a Norwegian study, which found that $83 \%$ of 185 in patients treated for alcohol and other drug abuse, scored above the cut-off for the Hopkins Symptoms Checklist-10 [44]. Distress prevalence was assessed for the week prior to treatment admission, a period, where psychological problems might culminate. Armstrong et al. in a study on 420 drug injecting male users participating in needle-and syringe programs in Delhi, India also found extremely high rates of $84 \%$ of participants with depressive and $71 \%$ with anxiety symptoms measured by the PHQ-9 [18]. In this case the study population was considerably more socially disadvantaged than the present study, with high proportions being illiterate, homeless and living with very small income/being dependent on scavenging.

For the present study it might be argued that given the timing and reference period for distress assessment, the prevalence rate particularly reflects the intensely stressful phases before entering treatment and early days of treatment, this overestimating distress levels in terms of a longer-term and more stable experience in need of psychiatric/psychological treatment. Despite this caveat, proportions of patients suffering from psychological comorbidity are sizeable. And while it remains unclear to which extent development of SUDs and/or being in treatment for SUDs causes distress or prior distress and depression contribute to self-medication via substance use, the findings indicate a need for action, since these conditions, if left untreated are likely to increase the risk of poor health outcomes, of relapse after treatment, workplace productivity loss and even premature mortality $[45,46]$.

Our study also investigated a set of socio-demographic, behavioral, and psychosocial factors that may be important to consider in understanding the development of psychological distress symptoms among this population. In particular, we found that family functioning as measured by the APGAR-Scale was significantly negatively associated with the K6 distress score. Prior studies conducted in Western and Eastern countries have also reported that family dysfunction is strongly associated with mental disorders [47, 48]. Few studies, however, have so far provided support for the association between family functioning 
and psychiatric comorbidity in Nepal [49] and India [50]. A study by Krishnakumar et al. [51] in India revealed that sources of distress in the family could be parental deaths, inter-parental conflicts, unfulfilled needs and wants, mental illness, parental substance addiction, parental divorce and disharmony. That the family history of substance abuse might be a relevant factor, was also shown in a study by Neupane et al. with Nepalese patients being treated for AUD and where reported that parental problem drinking was related to major depression in social groups where alcohol consumption was considered taboo [7]. Deficits in family functioning may lead to experience of distress and subsequent increase in substance use. Moreover, Hosseinbor et al. found that individuals who do not have an intimate and supportive relationship within their family are more likely to be attracted by and inclined towards friends and groups of their own age and become more susceptible to using drugs in the social context of these peer groups, which again later may cause psychological problems [52].

Vice versa SUDs in a family member will very likely affect the family system and family relations in a negative way so that conflicts arise and relations deteriorate over time. Shyangwa et al. in a study on the families of patients with opium dependence syndrome in New Delhi showed that $75 \%$ of patients' spouses perceived a severe burden due to their husband's opioid dependence [53].

This study further demonstrated that having only primary education is associated with more psychological distress symptoms. This finding is consistent with the previous studies [54, 55]. People with less education may feel socially trapped and helpless and might experience more adverse situations which could directly contribute to the emergence of psychological distress [56]. Further, patients with lower educational attainment may have lesser knowledge and poorer coping skills to deal with their substance abuse problem and thereby increase psychological distress and poor quality of life.

Also, age was a significant and negative correlate of psychological distress symptoms suggesting that as age increases, the level of psychological distress decreases. This is supported by another study conducted in Nepal, investigating recent depressive symptoms in AUD patients [37]. In general, young age is an unstable period in life when one may be less able to deal with daily stress while coping with developmental tasks, particularly when during puberty major physical an psychological changes are experienced [37, 46]. Evidence also shows that family disputes and domestic violence in Nepal place youngsters at greater risk of distress [57]. Furthermore, age also affect distress via severity of drug use since drug use was highest in the younger group and severity of drug use was again associated with distress. The association between psychological distress and age underscores the need for detection, assessment and treatment of mental health problems at early ages among patients with SUDs.

Finally, this study found that drug use severity as measured by the DAST-10 was significantly positively associated with psychological distress symptoms as also reported elsewhere [44]. Higher drug consumption may lead to higher levels of compromised physical health, negative social consequences as well as self-esteem problems while higher levels of distress experience might also lead to higher drug usage levels. Further studies should use prospective data to identify pathways that connect family dysfunction, drug use, and psychological distress. Severity of alcohol use on the other hand was neither a univariate nor an independent correlate of distress. A possible reason for this absence of an association could be lack of variability in alcohol use, since non-use of alcohol was relatively infrequent in our study.

Gender and marital status, while being significant on the univariate level, no longer predicted psychological distress in the multivariate regression analysis. These factors very likely are associated with some of the other influences, particularly severity of drug consumption as well as family functioning. Once these more direct influence factors are entered into the equation, the more distal indicators loose relevance. Similarly, perceived stigma was significantly positively related to distress in the bivariate analysis, but there was no independent effect in the multivariable model. Here it is presumably the effect of family functionality, which makes a difference, since perception of stigma might be more likely where SUD patients experience conflictual relationships with their families.

Also, somewhat surprisingly, stressful events were unrelated to distress experience. However, it is important to consider that the study population was already highly strained group. When being admitted to a treatment center, many might have had a long past trajectory of drug abuse, social conflicts or economic problems with ensuing self worth problems behind them. Singular negative events might have relatively less to add to distress in such samples than in average groups of citizens. For such a highly burdened population group a more detailed assessment than the dichotomous question used in the present study might have generated different results. Thus, Liao et al. in a study with patients treated for heroin dependence in China used a detailed life event rating scale, explicitly listing different types of events, and found significant associations with anxiety and depression [43].

\section{Strengths and limitations}

This is one of the few studies, which surveyed psychological distress symptoms among patients with SUD in Nepal. Data were collected using standardized instruments, which strengthened the reliability of the collected data. However, several limitations of this study should be considered. First, 
the analyses were conducted with cross-sectional data and thus, no causal statements could be made. Secondly, data in our study were based on self-report and no clinical assessments or biomarkers, for instance, to investigate the history of drug and alcohol use in the recent past were included. Third, the study was limited by a lack of validation of the mental health outcome tools within a Nepalese population. Fourth, as already pointed out above, the chosen time reference for distress assessment may have led to overrepresentation of transitorily high distress experience due to acute crisis, withdrawal symptoms etc. Such a strong influence of situational effects might also have limited the possibility to detect associations between patient characteristics or social influences and distress experience. A fifth limitation involves sampling bias as the clinics in the study were conveniently selected and restricted to the urban Kathmandu valley area in the first place, thus restricting possibilities to generalize our findings to all substance users in Nepal. Finally, we did not conduct genderspecific analyses because it would have involved too small sub-samples (especially the female sample).

\section{Conclusions}

Psychological distress is a serious problem among patients with SUD in Nepal. Clinicians working with SUD patients should consider co-morbid psychiatric illness and therefore this group of population should routinely be screened for psychiatric co-morbidity. Younger age, lower levels of education, higher severity of drug abuse and lower family functionality may be important factors for psychological distress among SUDs in urban Nepal. If confirmed by future longitudinal studies such characteristics may assist in identifying groups at risk for comorbid psychological distress symptoms among patients with SUDs. Future treatment approaches for substance abuse must address co-existing mental illness in Nepal. If the treatment of substance addiction is limited only to medical interventions, it is unlikely to attain full effect. Therefore, an integrated approach to treatment of SUDs, including supportive educational strategies and interventions to teach coping skills in preventing substance addiction and psychological distress may be warranted. However, more research needs to be conducted to substantiate these findings and to better inform intervention studies aimed at improving social, behavioral and psychosocial functioning of patients with SUD. Moreover, longitudinal studies examining the factors associated with developing psychological distress among patients with SUD will be helpful in disentangling causal relations and identifying at an early stage those who are at risk. Future research should also aim to index the K6Scale in the Nepalese populations so that the tool and current data can be used to adequately estimate population prevalence of psychological distress.

\section{Acknowledgements}

We would like to give special thanks to the seven drug rehabiliation centers that participated in this study, including ASARA Rehabilitation Center, Sober Recovery Treatment and Rehabilitation Center, Our New House Treatment and Rehabilitation Center, First Step Treatment and Rehabilitation Center, Richmond Rehabilitation Center for Alcohol Users, Richmond Rehabilitation Center for Drug Users and Youth Vision for allowing us to carry out the study. We would also like to thank the staff and study participants who have taken part in the research. We would like to acknowledge Binod Aryal and Raju Acharya from RIC Rose Cooperation Nepal for their assistance in field works.

\section{Funding \\ The authors have no support or funding to report.}

\section{Availability of data and materials}

The data will not be shared because that includes confidential patient data.

\section{Authors' contribution}

BG and MA conceived this research work. BG performed the experiments, analysed the data, interpreted results, and wrote the first draft of the manuscript. AL initially supervised the study and contributed to the design and methods as well as the writing of the manuscript. BG, BPC, DPP, MA, AL and PK contributed in revision of the manuscript. All authors have read and approved the final version for publication.

\section{Competing interests}

The authors declare that they have no competing interests.

\section{Consent for publication}

Prior to the study participants were asked to provide written informed consent to participate in the study, which described in Nepali the nature and purpose of the study and the implications of taking part. The participants were assured that their personal information will be kept confidential and will only be used for the research purpose. The consent form clearly stated that the consent to participate also included the consent to publish the study.

\section{Ethics approval and consent to participate}

The study protocol received ethical approval from the Manipal College of Medical Sciences, Pokhara, Nepal. Written informed consent was obtained from each participant prior to recruitment into the study. Information regarding the purpose, confidentiality, the voluntary nature of the study as well as participants' right to withdraw from the study at any time was explained before conducting study.

\section{Author details}

${ }^{1}$ Center for Global Health, Department of Public Health, Aarhus University, Bartholins Allé 2, Building 1261, 2:15, DK-8000 Aarhus C, Denmark. ${ }^{2} N e p a l$ Development Society (NEDS), Bharatpur, Nepal. ${ }^{3}$ Department of Community Medicine and Public Health, Institute of Medicine, Tribhuvan University, Maharajgunj, Kathmandu, Nepal. ${ }^{4}$ Department of Public Health, School of Health and Allied Sciences, Pokhara University, Pokhara, Nepal. ${ }^{5}$ Department of Community Medicine, Manipal College of Medical Sciences, Pokhara, Nepal. ' Unit for Health Promotion Research, University of Southern Denmark, Niels Bohrs Vej 9, DK-6700 Esbjerg, Denmark.

Received: 9 December 2015 Accepted: 14 August 2016

Published online: 08 September 2016

\section{References}

1. Kessler RC, Wang PC. The descriptive epidemiology of commonly occurring mental disorders in the United States. Annu Rev Public Health. 2008;29:115-29.

2. Kessler RC, Chiu WT, Demler O, Walters EE. Prevalence, severity, and comorbidity of twelve-month DSM-IV disorders in the National Comorbidity Survey Replication (NCS-R). Arch Gen Psychiatry. 2005;62(6):617-27.

3. Regier DA, Farmer ME, Rae DS, Locke BZ, Keith SJ, Judd LL. Comorbidity of mental disorders with alcohol and other drug abuse. Results from the Epidemiologic Catchment Area (ECA) Study. JAMA. 1990;264(19):2511-8.

4. Sheidow AJ, McCart M, Zajac K, Davis M. Prevalence and impact of substance use among emerging adults with serious mental health conditions. Psychiatr Rehabil J. 2012;35(3):235-43. 
5. Wynn R. Prior psychotic episodes among patients in a substance abuse clinic. J Subs Use. 2007;12:127-32.

6. Degenhardt L, Whiteford HA, Ferrari AJ, Baxter AJ, Charlson FJ, Hall WD, et al. Global burden of disease attributable to mental and substance use disorders: findings from the Global Burden of Disease Study 2010. Lancet. 2013;382(9904):1575-86.

7. Neupane SP, Bramness JG. Prevalence and correlates of major depression among Nepalese patients in treatment for alcohol-use disorders. Drug Alcohol Rev. 2013;32(2):170-7.

8. Shakya DR, Shyangwa PM, Sen B. Psychiatric comorbidity in cases admitted for alcohol dependence. J Delhi Psych. 2009;12(2):252-7.

9. Albanese MJ, Clodfelter Jr RC, Pardo TB, Ghaemi SN. Underdiagnosis of bipolar disorder in men with substance use disorder. J Psychiatr Pract. 2006; 12(2):124-7.

10. Verheul R, van den Brink W, Hartgers C. Personality disorders predict relapse in alcoholic patients. Addict Behav. 1998;23(6):869-82.

11. Carpentier PJ, Krabbe PF, van Gogh MT, Knapen LJ, Buitelaar JK, de Jong CA. Psychiatric comorbidity reduces quality of life in chronic methadone maintained patients. Am J Addict. 2009;18(6):470-80.

12. Hasin D, Liu X, Nunes E, McCloud S, Samet S, Endicott J. Effects of major depression on remission and relapse of substance dependence. Arch Gen Psychiatry. 2002;59(4):375-80.

13. Mazza M, Mandelli L, Di Nicola M, Harnic D, Catalano V, et al. Clinical features, response to treatment and functional outcome of bipolar disorder patients with and without co-occurring substance use disorder: 1-year follow-up. J Affect Disord. 2009;115(1-2):27-35.

14. Galaif ER, Sussman S, Newcomb MD, Locke TF. Suicidality, depression, and alcohol use among adolescents: A review of empirical findings. Int J Adolesc Med Health. 2007;19(1):27-35.

15. Hoxmark E, Benum V, Friborg O, Wynn R. Reduction in mental distress among substance users receiving inpatient treatment. Int J Ment Health Syst. 2010;4:30.

16. Wang J, El-Guebaly N. Sociodemographic factors associated with comorbid major depressive episodes and alcohol dependence in the general population. Can J Psychiatry. 2004:49(1):37-44.

17. Pradhan SN, Adhikary SR, Sharma SC. A prospective study of comorbidity of alcohol and depression. Kathmandu Univ Med J. 2008;6(23):340-5.

18. Armstrong G, Jorm AF, Samson L, Joubert L, Singh S, Kermode M. Suicidal ideation and attempts among men who inject drugs in Delhi, India: psychological and social risk factors. Soc Psychiatry Psychiatr Epidemiol. 2014;49(9):1367-77.

19. Neupane SP, Bramness JB. Who seeks treatment for alcohol problems? Demography and alcohol-use characteristics of patients in taboo and nontaboo drinking groups attending professional alcohol services in Nepal. Asian J Psychiatr. 2014;12:82-7.

20. Central Bureau of Statistics. National Population and Housing Census. 2011, Central Bureau of Statistics: Kathmandu, Nepal. http://unstats.un.org/unsd/ demographic/sources/census/wphc/Nepal/Nepal-Census-2011-Vol1.pdf Accessed on 01.04. 2016.

21. Pandey JP, Dhakal MR, Karki S, Poudel P, Pradhan MS. Maternal and child health in Nepal: The effects of caste, ethnicity, and regional identity: further analysis of the 2011 Nepal Demographic and Health Survey. Calverton: Nepal Ministry of Health and Population, New ERA, and ICF International; 2011.

22. WHO-AIMS, Report on mental health system in Nepal. WHO and Ministry of Health, Kathmandu, Nepal. 2006. http://www.who.int/mental_health/evidence/ nepal_who_aims_report.pdf. Accessed on 12.10.2015.

23. Kessler RC, Green JG, Gruber MJ, Sampson NA, Bromet E, Cuitan M, et al. Screening for serious mental illness in the general population with the K6 screening scale: results from the WHO World Mental Health (WMH) survey initiative. Int J Methods Psychiatr Res. 2010;19 Suppl 1:4-22.

24. Kessler RC, Üstün TB. The WHO world mental health survey: global perspectives on the epidemiology of mental disorders. UK: Cambridge University Press; 2008.

25. Harvard Medical School, National Comorbidity Survey; 2005. http://www hcp.med.harvard.edu/ncs/. Accessed 29 Oct 2015.

26. Pyakuryal A, Tausig M, Subedi S, Subedi J. Strangers in a familiar land: the psychological consequences of internal migration in a developing country Stress Health. 2011;27(3):e199-208.

27. Swartz JA, Lurigio AJ. Screening for serious mental illness in populations with co-occurring substance use disorders: Performance of the K6 scale. J Subst Abuse Treat. 2006;31(3):287-96.
28. Fushimi M, Saito S, Shimizu T, Kudo Y, Seki M, Murata K. Prevalence of psychological distress, as measured by the Kessler 6 (K6), and related factors in Japanese employees. Community Ment Health J. 2012;48(3):328-35.

29. Kessler RC, Barker PR, Colpe $\sqcup$, et al. Screening for serious mental illness in the general population. Arch Gen Psychiatry. 2003;60(2):184-9.

30. Babor TF, Higgins-Biddle JC, Saunders JB, et al. The Alcohol Use Disorders Identification Test (AUDIT): Guidelines for Use in Primary Care. World Health Organization, Department of Mental Health and Substance Abuse; 2001.

31. Skinner H. The DAST-10 (Centre for Addiction and Mental Health, Canada). 2009.

32. Luoma JB, O'Hair AK, Kohlenberg BS, Hayer SC, Fletcher L. The development and psychometric properties of a new measure of perceived stigma toward substance users. Subst Use Misuse. 2010;45(1-2):47-57.

33. Smilkstein $\mathrm{G}$. The Family APGAR: a proposal for a family function test and its use by physicians. J Fam Pract. 1978;6:1231-39.

34. Victora CG, Huttly SR, Fuchs SC, Olinto MT. The role of conceptual frameworks in epidemiological analysis: a hierarchical approach. Int J Epidemiol. 1997;26(1):224-7

35. Cronbach $L$. Coefficient alpha and the internal structure of tests. 1951. p. 297-334

36. Softonic. http://spss.en.softonic.com/. Accessed 29 Oct 2015.

37. Clarke K, Saville N, Shrestha B, Costello A, King M, Manandhar D, et al. Predictors of psychological distress among postnatal mothers in rural Nepal: a cross-sectional community-based study. J Affect Disord. 2014;156:76-86.

38. De Almeida F, Simon G, Herman H, Bushnell D, Martin M, Patrick D, et al. Major depression and its correlates in primary care settings in six countries. 9-month follow-up study. Br J Psychiatry. 2005;186:41-7.

39. Kohrt BA, Speckman RA, Kunz RD, Baldwin JL, Upadhaya N, Acharya NR, et al. Culture in psychiatric epidemiology: using ethnography and multiple mediator models to assess the relationship of caste with depression and anxiety in Nepal. Ann Hum Biol. 2009;36(3):261-80.

40. Neupane SP, Lien L, Martinez P, Hestad K, Bramness JG. The relationship of alcohol-use disorders and depressive symptoms to tryptophan metabolism: cross-sectional data from a Nepalese alcohol treatment sample. Alcohol Clin Exp Res. 2015;39(3):514-21.

41. Pillai A, Andrews T, Patel V. Violence, psychological distress and the risk of suicidal behaviour in young people in India. Int J Epidemiol. 2009;38(2):459-69.

42. Reid P, Mann R, Strike C, Brands B, Khenti A. Comorbidity between psychological distress and drug use among patients in treatment centres in Jamaica: implications for policies and programme design. Texto \& Contexto Enfermagem. 2012;21:133-40.

43. Liao Y, Tang J, Liu T, Chen X, Liu X, Hao W. A pilot study of life events and mood disorders: self-report survey in chinese heroin-dependent individuals. Am J Addict. 2011;20(4):337-42.

44. Hoxmark E, Nivison M, Wynn R. Predictors of mental distress among substance abusers receiving inpatient treatment. Subst Abuse Treat Prev Policy. 2010;5:15.

45. Landheim AS, Bakken K, Vaglum P. Impact of comorbid psychiatric disorders on the outcome of substance abusers: a six year prospective follow-up in two Norwegian counties. BMC Psychiatry. 2006;6(1):1-11.

46. Sinha R. Chronic stress, drug use, and vulnerability to addiction. Ann N Y Acad Sci. 2008;1141:105-30.

47. Huang JP, Xia W, Sun $\mathrm{CH}$, Zhang HY, Wu L. Psychological distress and its correlates in Chinese adolescents. Aust N Z J Psychiatry. 2009;43(7):674-80.

48. Armsden GC, McCauley E, Greenberg MT, Burke PM, Mtchell JR. Parent and peer attachment in early adolescent depression. J Abnorm Child Psychol. 1990;18(6):683-97.

49. Lamichanne N, Shyangwa PM, Shakya R. Family burden in substance dependence syndrome. 2008.

50. Chhabra GS, Sodhi MK. Impact of family conflict on the psychosocial behaviour in male adolescents. J Nep Paediatr Soc. 2012;32(2):124-31.

51. Krishnakumar P, Geeta MG, Riyaz A. Deliberate self harm in children. Indian Pediatr. 2011;48(5):367-71.

52. Hosseinbor M, Bakhshani NM, Shakiba M. Family functioning of addicted and non-addicted individuals: a comparative study. Int J High Risk Behav Addict. 2012;1(3):109-14.

53. Shyangwa PM, Tripathi BM, Lal R. Family burden in opioid dependence syndrome in tertiary care centre. J Nepal Med Assoc. 2008:47(171):113-9.

54. Alem A, Kebede D, Woldesemiat G, Jacobsson L, Kullgren G. The prevalence and socio-demographic correlates of mental distress in Butajira, Ethiopia. Acta Psychiatr Scand. 1999;397:7. 
55. Husain N, Chaudhry N, Jafri F, Tomenson B, Surhand I, Mirza, et al. Prevalence and risk factors for psychological distress and functional disability in urban Pakistan. WHO South-East Asia J Public Health. 2014; 3(2):144-53.

56. Dalgard OS, Mykletun A, Rognerud M, Johansen R, Zahl PH. Education, sense of mastery and mental health: results from a nation wide health monitoring study in Norway. BMC Psychiatry. 2007;7:20.

57. Upadhaya N. "Distress, a door to happiness?" The meaning and etiology of everyday adolescent distress, in a Nepalese government high school. Faculty of Social and Behavioral Sciences. University of Amsterdam, the Netherlands; 2011. p. 85. http://amma.socsci.uva.nl/theses/upadhaya.pdf. Accessed on 01.04.2016

Submit your next manuscript to BioMed Central and we will help you at every step:

- We accept pre-submission inquiries

- Our selector tool helps you to find the most relevant journal

- We provide round the clock customer support

- Convenient online submission

- Thorough peer review

- Inclusion in PubMed and all major indexing services

- Maximum visibility for your research

Submit your manuscript at www.biomedcentral.com/submit
) Biomed Central 